\title{
Scripta
}

Revista Internacional de Literatura i Cultura Medieval i Moderna

International Journal of Medieval \& Modern Literature \& Culture

\section{La música polifónica flamenca del segle XV a les novel les clàssiques catalanes Titant lo Blanc \& Curial e Güelfa}

\section{Flemish polyphonic music of the 15th century in the classical Catalan novels Tirant lo Blanc \& Curial e Güelfa}

\author{
Bob De Nijs \\ bobdenijs@hotmail.com \\ Institut d'Estudis Catalans
}

Resum: Al Tirant lo Blanci al Curial e Güelfa hi ha referències concretes al coneixement possiblement directe que els autors tenien sobre la música polifònica flamenca, que entrà a Itàlia pel nord durant la primera meitat del segle XV i arribà a Nàpols.

Paraules clau: Tirant lo Blanc; Curial e Güelfa; polifonia flamenca a Itàlia; cultura europea del segle XV

Abstract: There are specific references in Tirant lo Blanc and Curial e Güelfa to the probably direct knowledge that the authors had on Flemish polyphonic music, which came to the north of Italy during the first half of the fifteenth century and arrived in Naples.

Keywords: Tirant lo Blanc; Curial e Güelfa; Flemish polyphonic music in Italy; fifteenth century European culture 
Bob de Nijs. La música polifònica flamenca del segle XV a les novel les clàssiques catalanes Tirant lo Blanc \& Curial e Güelfa

Si Johan Huizinga hagués pogut llegir els clàssics catalans del segle XV, Tirant lo Blanc i Curial e Güelfa, potser hauria pogut treure'n conclusions semblants a les que va formular, després de moltes investigacions i anàlisis de textos dispersos, a la seva obra, Herfsttij der Middeleeuwen (1919), i on dictamina, entre altres conclusions: «El final de l'època medieval demostra tota una visió del món que s'extingeix». La forma simbòlica de pensament havia perdut vigència i la creació d'al legories i de símbols ja s'havia convertit en un joc va, una fantasia superficial sobre un sol fil d'idees. El conformisme basat en la interpretació del món perfecte de la cavalleria es convertia diàriament en una mentida amagada darrere d'una retòrica i d'unes formes de comportament purament artificioses. Literàriament parlant, ja sols l'episodi de la presència de Tirant a la cort anglesa (Martorell 1990: caps. XL-XC) dóna una imatge minuciosa de l'ambient ideològic que hi regnava, de manera que podem tenir per testimoniatge històric aquests capítols. Fora dels fets d'armes, crida l'atenció la construcció d'una roca artificial de fusta, amb castell i tot, que serveix per a representar un joc teatral ple d'al legories. És un ambient molt similar al que Huizinga pogué constatar a la cort dels ducs de Borgonya. Un artifici semblant i tan enginyós com el que descriu Joanot Martorell a la seva novel la és, per exemple, el famós faisà -amb músics i tot a dins- que va presidir el ressonant voeu du faisan (1454) amb què el duc va fer prometença d'organitzar una croada contra els turcs -amb la reconquesta inclosa de Constantinoble, ciutat caiguda en mans del soldà turc l'any anterior. Gesta que, per cert, Joanot Martorell farà realitzar al seu heroi, Tirant, imaginàriament, més endavant. Tot, però, quedà en fals, malgrat certes preparacions reals i la recaptació de contribucions peculiars -una disfressa que difícilment amaga el seu caràcter d'oportunisme.

Les raons del viatge de Joanot Martorell a Anglaterra, a causa del conflicte amb Joan de Montpalau $-\mathrm{i}$, de fet, tots els viatges de Joanot Martorell tenien a veure amb disputes i reptes que podem detectar a les Lletres de Batalla- i totes les seves accions personals ja sols foren productes de les absurditats que regien els compliments de convencions obsoletes i que, precisament en el cas de l'autor del Tirant, conduïen a la ruïna personal i familiar (Villalmanzo \& Chiner 1992: 2).

Igual que Huizinga, podem constatar també l'eclosió intensa d'un món estètic que es tradueix en l'evolució artística, pictòricament palpaple, en les obres dels pintors que giraven entorn de la cort borgonyona, com Jan van Eyck, Hans Memling i tot un seguit de pintors flamencs, que havien de contribuir a l'enaltiment d'una potència política naixent que es tornava cada cop més independent del seu centre i senyor feudal, la cort de França, mentre durava un conflicte entorn de la corona francesa (la guerra de Cent Anys, que s'acabaria en 1453), que els reis d'Anglaterra cobejaven amb èxit canviant. Com que els ducs de Borgonya tenien l'ambició de conquerir un lloc determinant a l'escenari internacional, de vegades s'aliaven i es relacionaven amb els interessos anglesos. Aquesta situació promovia no sols l'economia llanera entre Flandes i Anglaterra, sinó que també, des del punt de vista cultural, feien viatjar tota mena d'obres literàries, ${ }^{1}$ plàstiques i musicals d'un costat a l'altre. La forma cultural de la música d'aquella època era la polifonia flamenca que al segle

1 Per exemple, l'obra flamenca 'Elckerlijck', va ser l'original sobre el qual es basa el text anglès de 'Everyman'; en 1911 Hugo von Hofmannsthal va escriure una versió alemanya: 'Jedermann'.

SCRIPTA, Revista internacional de literatura i cultura medieval i moderna, núm. 2 / desembre 2013 / pp. 34-45 ISSN: 2340-4841 · doi:10.7203/SCRIPTA.2.3100 
Bob de Nijs. La música polifònica flamenca del segle XV a les novel les clàssiques catalanes Tirant lo Blanc \& Curial e Güelfa

$\mathrm{XV}$ va tenir un apogeu remarcable. ${ }^{2}$ Menys palpable que les obres pictòriques a causa de la seva categoria peculiar lligada al temps i a l'espai, aquesta música, amagada i desconeguda durant molts segles, ens va ser transmesa a través de manuscrits - muts, això sí- sovint luxuosament il lustrats. Curiosament, tant el Tirant com el Curial fan menció de la música culta que els autors respectius havien de sentir sense dubte en més d'una ocasió, car formava part de les cerimònies religioses o de les interpretacions cortesanes del seu temps $i$ als ambients que freqüentaven, i escoltantles podien reconèixer-les i situar-les mentalment, atés que, tal com constaten Ferrando \& Martín (2010: 787), la música formava part de l'educació com «una disciplina propia de les arts liberals, dins del quadrivium».

La polifonia primitiva va nèixer a base de veus que cantaven en quarts de to paral lels les melodies gregorianes (segle XI), a distància de quarta, quinta o octava, mentre els intervals en terceres foren considerats diabolus in musica durant molt de temps. ${ }^{3}$ Precisament és la música religiosa de l'església romana la que anava a determinar el color de la música culta dels segles següents. Al segle XII, al cant gregorià es començava a afegir una veu que es movia individualment $\mathrm{i}$ independentment del seu fonament. La meravella d'aquella polifonia recau en les línies melòdiques independents amb una «verticalitat cada vegada més acusada (simultaneitat dels sons) enfront de l'horizontalitat (serie de sons temporals encadenats en el temps) de la melodia, fent cada vegada més evident la seua independència d'aquesta» (Ferrando \& Martín 2010: 792). La cohesió de les veus independents es produeix en uns punts crucials -el principi i el final d'un fragment musical- en octaves, unísons o en quintes. En el curs dels segles XIII i XIV, aquesta polifonia es tornava cada cop més complexa per la introducció d'una tercera i quarta veu. És aleshores quan els compositors del moment sentien la necessitat d'una certa organització del sistema musical quant a la relació recíproca dels elements melòdics i la cohesió rítmica. Al segle XV, l'època en què foren escrites les dues novel les clàssiques de la literatura catalana, ja es cantaven les diferents parts simultàniament en un estil polifònic sense cap jerarquia dominant d'una veu, harmònicament parlant. Neixen alhora noves formes de composició -el contrapunt imitatiu, amb una escriptura que crea finalment el cànon com a cant particular, i que a Itàlia es convertia en la caccia- i de forma -el motet i el madrigal del Trecento. Característic de la polifonia flamenca és l'eufonia que regeix la virtuositat tècnica i l'equivalència

2 El terme polifonia flamenca es refereix a l'escriptura compositiva i el repertori que n'és el producte que durant gairebé dos segles cinc generacions de compositors van crear. Molts mestres provenien d'Anvers, de Turnhout, Lieja i Atrecht (actualmente Arras, a França). Per aquesta raó es pot defensar la denominacó de 'polifonia flamenca', malgrat que alguns, tot i ser originaris dels Països Baixos meridionals, parlaven francès, i per això en publicacions angleses i franceses es parla de 'polifonia franco-flamenca. Amb tot, els italians es limiten al terme fiamminghi.

3 Els primers fragments de música polifònica es troben en dos petits manuals, Musica Enchiriadis i Scholica Enchiriadis, amb instruccions i exemples musicals de com es podia afegir a la melodia gregoriana existent una segona veu (Bossuyt 1994: 22). Per la seva banda, Ferrando \& Martín (2010: 789) es refereixen al tractat del monjo Oliba Breviarium de Musica que revela «coneixement teòric de la polifonia al nostre entorn». Aquest tractat «inclou la còpia dels dos textos amb notació musical polifònica més antics, tots dos de finals del segle IX». Podrien ser referències als dos manuals mencionats. 
Bob de Nijs. La música polifònica flamenca del segle XV a les novel les clàssiques catalanes Tirant lo Blanc \& Curial e Güelfa

de les veus. I és que es produeix un fenomen curiós: al món de la creació culta es constata una certa secularització; a la pintura típicament flamenca s'esborra el predomini religiós i els elements pictòrics poden ser tant religiosos com seculars - una Verge o un Crist ja no són tractats de manera diferent que els retrats de les figures seculars que escènicament els acompanyen, una equivalència que evolucionarà, amb el temps, cap a un llenguatge pictòric autònom.

Una cosa semblant passa amb la música: malgrat la resistència del sector eclesiàstic, ja al segle XIV els compositors, els creadors de l'ars nova ${ }^{4}$ de França -amb el seu seguidor més important, Guillaume de Machaut (1300-1373)-, usaven textos de poemes d'alta volada o inclús de caire popular. També les capelles musicals ja no eren privilegi de les esglésies o de les abadies: les corts principesques també començaven a crear les seves pròpies capelles on hi podien intervenir també instruments. Els prínceps rivalitzaven entre ells per a poder atreure els millors músics del moment. Un centre prepoderant era la cort de Borgonya; i pels llibres de comptabilitat dels ducs borgonyons sabem que hi rebien músics de tot el món. Això permetia i promovia intercanvis d’influències musicals. La diferència entre la música religiosa i la secular consistia generalment en el fet que per a les chansons es preveien tres veus, mentre que les misses en requerien quatre -encara que existien excepcions: cançons i motets escrits per quatre veus, i misses a tres veus. Però, amb tot i això, la diferència compositiva entre una i l'altra forma s'esborrava cada vegada més. Per això, moltes misses es basen sobre una cançó popular que serveix de tema conductor o de cantus firmus reservat per al tenor. ${ }^{5}$

Hem de tenir en compte tots aquests elements, si volem comprendre les referències musicals que trobem, tant al Tirant com al Curial. Perquè, precisament, no es tracta només de les mencions de cants i de balls, d'instruments o d'algun magnificat com el que trobem al Tirant (Martorell 1990, I: 69) -que no hi són descrits en terminologia musical-, sinó de la música culta, la música polifònica de la mateixa època dels autors de les dues novel les. Ens hi trobem amb mencions musicals que ens donen una imatge excepcional i sorprenent de circumstàncies, de formes d'interpretació i de l'estil artístic.

Comencem amb el Tirant, on trobem un fragment que revela l'ús d'un tipus de música particular i religiosa que Joanot Martorell va conèixer indubtablement. Encara que l'episodi sigui situat a Stagira, durant la reconquesta de l'imperi grec per Tirant (caps. CCCCXIV-CCCCLXX), el moment musical es refereix clarament a experiències viscudes per l'autor al seu entorn circumstancial, que poden ser l'assistència a actes religiosos amb interpretacions musicals

\footnotetext{
4 El terme ars nova es refereix al tractat de Philippe de Vitry (1291-1361), bisbe de Meaux, que durant molt de temps va influir la música polifònica a França.

5 Moltes misses es van composar, per exemple, a base de la cançó L’homme armé. Guillaume Dufay va composar una missa que porta aquest nom, quan treballava a la cort de Borgonya (1460). Finalment, van arribar a ser més de trenta misses que tenen com a cantus firmus la mateixa cançó popular anònima. Dufay, Ockeghem i Busnois són els que van usar en primer lloc el famós tema musical per a les seves misses polifòniques.
} 
Bob de Nijs. La música polifònica flamenca del segle XV a les novel les clàssiques catalanes

Tirant lo Blanc \& Curial e Güelfa

puntuals durant els seus viatges a Anglaterra (febrer 1438 - septembre 1439) i a Nàpols (octubre 1440 - març 1442):

Com foren dins la sglésia, l'ofici se començà molt singular, car aquí eren los chantres de la capella de Tirant e los de la capella del rey Scariano, e lo bisbe dix la missa, e era tant la remor de la plasent música, que los moros n’estaven molt admirats e tenien notícia de la gran perfecció de la ley crestiana (Matorell 1990, I: 879).

Dues coses ens criden l'atenció: hi ha, en primer lloc, la menció de les dues capelles, la de Tirant i la del rei Escariano. Això ja ens indica una presència que correspon a la realitat del moment que va viure en Joanot Martorell. Ja hem mencionat els intercanvis que podien fer els músics en qüestions professionals, cosa que afavoria l'evolució estilística de la polifonia. Quan Martorell parla de la plasent música, es refereix a una sonoritat que és agradable per a l'oïda, una mena de dolce stil nuovo musical. Després que l'ars nova de França -amb París com a centre principal- havia donat a la polifonia musical una llibertat extrema i una complexitat tècnica ja insuperables, la necessitat de transparència musical hi era ineludible. I és precisament a Anglaterra on compositors com John Dunstable (1390-1453) i Lionel Power (1370/1385-1445) començaven amb un estil polifònic més agradable, més eufònic, amb altres intervals, que aviat s'imposaria al continent, principalment a l'entorn de la cort borgonyona, on se l'anomenarà contenance angloise. Martin le Franc va dedicar uns versos als intercanvis musicals que ocorrien en aquella època en el seu extens poema Le champion des dames:

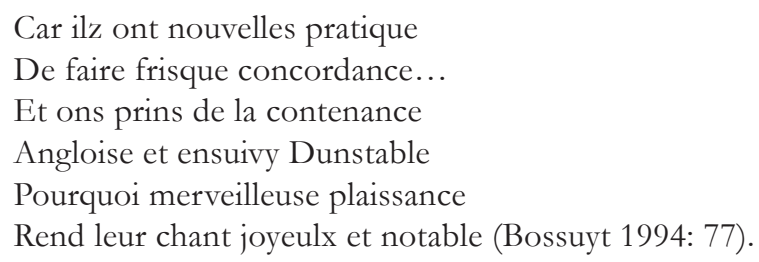

El pronom ilz del primer vers es refereix precisament a Guillaume Dufay i a Gilles Binchois, els dos compositors que escoltaven amb molta fascinació les interpretacions de dos ministrils anglesos, cecs, i que són els que s'adheririen al nou estil i l'elevarien a les possibilitats màximes d'expressió. Si tenim en compte dues paraules semblants i del mateix significat -plaissance al poema de Martin le France, i plasent en el Tirant-, podem entendre que la plasent música de què ens parla Joanot Martorell correspon a una qualificació generalitzada amb què era acceptada la música interpretada per les capelles principesques que ell va conèixer en primer lloc a Anglaterra. I es tractaria, doncs d'una música que estilísticament s'havia apartat ja de la polifonia del segle XIV que havia dominat arreu de l'Europa occidental.

Un fet històric que influirà definitivament la propagació del nou estil polifònic i que determinarà definitivament l'aspecte musical del segle XV, serà el concili de Constança (1414-1418). En aquella ciutat no sols es reuniran les autoritats eclesiàstiques amb intenció de resoldre el Cisma d'occident, sinó que s'hi acostaran també les corts seculars de l'emperador, d'alguns reis i de prínceps de tot 
Bob de Nijs. La música polifònica flamenca del segle XV a les novel les clàssiques catalanes Tirant lo Blanc \& Curial e Güelfa

arreu. Tant les autoritats eclesiàstiques com les seculars es faran acompanyar per les seves capelles. ${ }^{6}$ Això permetrà als 1700 músics allà reunits, conèixer - escoltant les interpretacions contínues- els nous estils i bescanviar les novetats musicals. O, inclús, hi canviaran de patró i de capella. I, de fet, va ser realment un encontre massiu de músics de França, d'Alemanya, d'Anglaterra i de les Espanyes, cosa mai vista i que no es va repetir mai més.

Un dels més grans compositors que hi va fer acte de presència, en companyia del seu senyor, fou el ja mencionat Guillaume Dufay (1397-1474), ${ }^{7}$ que, després de tornar un moment a Kamerijk -ara Cambrai, a França-, viatjà a Itàlia, on es posà a disposició de la familia Malatesta (1420-1424); sabem que l'any 1427 era a Bologna, i després formà part de la capella papal a Roma (1428-1433); i ens consta que, finalment, fou director de la capella de la cort de Savoia (1434-1435). Tota una vida, doncs, de molts moviments d'un costat a l'altre, que li va permetre ampliar els seus coneixements i els seus benificicis materials. D'altres compositors que deixaven la seva petja en aquell món musical particular eren Johannes Ockeghem (1410-1497) i Gilles Binchois (1400-1460). Aquest últim va treballar a Anglaterra, al servei del comte de Suffolk, i va ser membre de la capella dels ducs de Borgonya.

Si menciono aquests fets i aquestes dades és perquè precisament es tracta de contemporanis de Joanot Martorell i potser de l'autor anònim del Curial i que van determinar el color musical de l'època. Acabat el concili de Constança, la capella papal d'Avinyó tornà a Roma -una mica tard, el 1443-, on, com hem vist, hi va romandre durant cinc anys Guillaume Dufay. Gràcies al moviment provocat pel concili, Itàlia començava a absorbir les noves tendències musicals. Aquella regió havia conegut un moviment polifònic, el Trecento, que es desenvolupava paral lelament a l'ars nova, degut als intercanvis i contactes amb músics i compositors francesos durant el segle XIV, i va donar primordialment una florida accentuada de cançons mundanes. ${ }^{8}$ La música del XV, és a Itàlia una vertadera «invenció flamenca» (Festa 2012: 28). El fet de tants músics viatjant per les corts italianes, i la consolidada fama de les escoles musicals a àrees de dominació borgonyona (Cambrai, Bruges, Lieja, Tournai, Anvers), on els futurs professionals musicals conclö̈en llur formació, permetia la introducció definitiva de la polifonia flamenca.

També Nàpols es convertí en un centre musical important, on tenim constància de la presència del compositor flamenc Johannes Tinctoris - de fet, es deia Teinturier o de Vaerwere-, el 1472. Encara que aquest músic és conegut principalment pels seus tractats musicals, la seva importància

$6 \mathrm{Al}$ concili de Constança pariciparen 103 bisbes, 18000 eclesiàstics, entre capellans, abats, monjos i teòlegs. Hi anaven més de 50.000 visitants (Weber 2000: 32).

7 Guillaume Dufay acompanyava Jehan de Lens, bisbe de Kamerijk (Cambrai), com a membre de la capella episcopal. S'hi va trobar també amb el cardenal Pierre d'Ailly, personatge molt important en l'ambient del mateix concili i que havia sigut bisbe de Cambrai del 1397 fins al 1411. De fet, Dufay era un dels 1700 músics que donaven brillantor a les cerimònies del concili (Weber 2000).

8 Que els intercanvis eren recíprocs, ho demostra la figura de Johannes Ciconia (Lieja, 1370 - Padua 1412). Aquest compositor, pels seus contactes a Itàlia, adoptava bastants formes del Trecento musical. 
Bob de Nijs. La música polifònica flamenca del segle XV a les novel les clàssiques catalanes Tirant lo Blanc \& Curial e Güelfa

com a compositor no ho és menys, i podem entendre que amb la seva arribada a Nàpols no s'hi introduïa una novetat de cop i volta, sinó que venia a continuar i a afegir-hi més esplendor a una situació d'alta qualitat musical ja existent. Quan l'any 1454 Martorell va fer estada a la cort del Magnànim, a Nàpols, la música polifònica flamenca, doncs, ja havia penetrat en aquella ciutat meridional d'Itàlia, que no sols era un lloc on la música tenia un cert pes, sinó també un centre cortesà important d'una cultura exquisida. ${ }^{9}$ Els músics que hi treballaven, o provenien de les regions nòrdiques, o s'havien imbuït de l'estil del nord que en certa manera completava la pròpia manera de sentir i d'expressar-se musicalment -és a dir, el seu ars subtilior-, fins l'arribada dels compositors flamencs no havia donat creacions de gran envergadura: era una música refinada, però de formes més reduïdes. ${ }^{10}$

Si juntem les dades històriques amb la menció de les capelles musicals, podem ja arribar a la conclusió que Joanot Martorell va conèixer la música polifònica del seu temps en la seva forma eufònica, tal com va néixer a Anglaterra, on ell va tenir contactes durant la visita ja mencionada, $i$ després, a la cort de Nàpols, potser ja en una forma més evolucionada d'aquella que va escoltar a Anglaterra, a causa de la gran empenta que van donar-hi els creadors flamencs. Que no podia ser a València o Barcelona, no és perquè fos per absència de contactes entre els territoris dels ducs de Borgonya i els de la península ibèrica; aquestes relacions ja existien abans, però a base de cantants individuals $i$ instrumentistes, $i$ no amb figures musicals rellevants en el camp de la composició -perquè hi continuava encara l'estil polifònic sorgit de l'ars nova. Entre Nàpols i València -i, més encara, entre Nàpols i Gandia- hi va haver un corrent cultural -i musical- bastant important. Però haurem d'esperar fins a l'arribada de Felip el Bell, que hi va dur la seva «capella flamenca», per a poder constatar l'eclosió àmplia i definitiva de la polifonia flamenca al món ibèric. ${ }^{11}$

$\mathrm{Al}$ costat de la presència de les capelles musicals amb caràcter ben definit, ens trobem en aquest fragment també davant un fenomen molt curiós que pot sorprendre el lector actual, d'una mentalitat més aviat racional i dialèctica, però que en aquella època era molt corrent, és a dir, «la bellesa com a prova de la veritat religiosa». Això no és un invent del nostre autor, car, de fets semblants se'n produïren, per exemple, durant el curs històric de la formació dels regnes i dels estats medievals. Com a exemple, tenim referència de la conversió de Vladimir, príncep de Kíev, que es deixà convèncer per la realitat sensible de la religió cristiana, desprès d'haver estudiat també altres formes religioses. És clar que, en aquest cas, el que Vladimir cercava, potser no era la veritat absoluta expressada en

9 A Nàpols es van trobar sis misses que a base d'estudis estilístics es poden atribuir a Antoine Busnois (1430-1492). D‘altra banda, l'any 1453 residí a la cort del Magnànim Juan Cornago (1400-1475), un compositor de la transició entre l'ars nova i el renaixement.

10 Al segle XIV, hi havia el florentí, Francesco Landini (1325-1397), un compositor que havia donat una forma exquisida a la ballata, que despertava després l'admiració dels polifonistes flamencs del segle XV, com Dufay, que va fer dues versions de la ballata «Invidia nemica».

$11 \mathrm{Al}$ servei de Carles V, després, trobarem els compositors Nicolaas Gombert i Thomas Crequillon. 
Bob de Nijs. La música polifònica flamenca del segle XV a les novel les clàssiques catalanes Tirant lo Blanc \& Curial e Güelfa

una religió o una altra; el que importava era trobar un símbol i una estructura que li pogués servir de mitjà globalitzador i convincent per a reunir els pobles diversos que formaven el seu regne. A fi de convèncer els seus súbdits de la seva superioritat i del seu lideratge inqüestionables, la bellesa litúrgica de l'església bizantina li devia d'anar molt bé per enlluernar els seus súbdits. ${ }^{12}$

Encara que la conversió del príncep de Kíev no té res a veure amb les nostres novel les clàssiques catalanes, cito aquests fets històrics perquè permeten fer comparacions amb les escenes narrades al Tirant i al Curial, particularment respecte a la importància que tenia la bellesa com a factor de persuació. Qui conegui una mica la litúrgia bizantina, sap el relleu que hi tenen tots els elements que condueixen a aquella bellesa que obté valor teològic decisiu amb els seus efectes sobre la sensibilitat dels sentits humans. És una situació d'impacte emotiu, a la qual es refereix Martorell, quan descriu escenes com la que he mencionat més amunt.

Tanmateix, a la novel la passa una cosa molt curiosa, en la descripció de l'ambient bizantí, tant a la ciutat de Constantinoble i a la cort, com fora de la capital imperial: en cap moment l'autor no fa menció de les discussions teològiques, de les diferències litúrgiques i del cisma que dividia la cristiandat des del segle XI, entre les esglésies ortodoxes i les de l'obediència romana. Tracta el món cristià com un sol bloc homogeni amb només un sol adversari: el món de l'islam. Suposant que Martorell només devia conèixer la litúrgia de casa seva, és a dir, la de l'església catòlica i romana, ens podem demanar de quina música es tracta aquí, quines són les formes musicals que enlluernen els moros de la novel la de Joanot Martorell i que tenen la funció clara d'establir el valor teològic de la bellesa.

Vist que l'autor no diu res de les particularitats bizantines i ortodoxes, o si més no, de la pràctica d'aquestes particularitats, no sabem si realment és una actitud voluntària per no complicar la trama narrativa amb qüestions teològiques espinoses o si, simplement, no formava part dels seus esquemes de reflexió. Martorell es limita a suggerir que es tracta d'una música culta d'un alt grau de bellesa. Al seu temps, efectivament, aquesta música existia, però, encara que ja hem pogut deduir dels elements històrics -els viatges-i narratius -l'estada de Tirant a Anglaterra, les capelles-, quin era l'estil musical que formava part de les experiències del nostre autor valencià? Al Tirant ens falta una caracterització directa de la música de la qual parla i que identifica amb la categoria de la bellesa.

Ja sabem que per l'educació rebuda, Martorell havia de conèixer formes musicals de la polifonia imperant, la que s'havia desenvolupat a partir de l'ars nova de Philippe de Vitry. Forçosament devia haver descobert, a base dels seus coneixements, una forma més evolucionada d'aquesta polifonia a Anglaterra i a Nàpols. Però només ens parla de les formes interpretatives i dels efectes sobre els oïdors.

12 Els informadors li varen donar la clau amb paraules següents: «No sabíem si érem al cel o a la terra, perquè no hi ha res a la terra amb tanta elegància i tanta bellesa, i no sabem què dir-ne; només sabem que Déu hi és present entre els homes. No podem oblidar aquella bellesa» (Averintsev 1988: 8-13). 
Bob de Nijs. La música polifònica flamenca del segle XV a les novel les clàssiques catalanes Tirant lo Blanc \& Curial e Güelfa

$\mathrm{Al}$ Curial e Güelfa hi ha més elements que permeten rastrejar els sons musicals que va conèixer el nostre autor anònim, que devia de tenir un bagatge cultural molt ampli. Al començament de la tercera part de la seva novel la, fa una exposició teòrica sobre la veu, el cant i l'expressió vocal a base de la simbología mítica de les muses (Ferrando \& Martín 2010: 789). Fa, però, també, menció de la pràctica del cant polifònic en ús, quan descriu com, a casa de Fàtima i de sa filla Camar, «aquells catius, qui maravellosament cantàvan» (Curial 1933, III: 110). O com la mateixa Camar s'entreté cantant: «Cantava molt bé Camar, e Johan mostrà-li moltes cançons, e ab acorts cantava ab ella» (Curial1933, III: 110). ${ }^{13}$ La polifonia de què es parla aquí es pot situar, pel que respecat a les formes, en dos orígens: podria ser una forma de la chanson francesa -en aquest exemple, a dues veus, i no a tres o a quatre, com podia ser-, producte de la secularització creixent del moviment polifònic, i que tenia als segles XIV i XV una gran difusió a les corts europees; o pertany a l'ars subtilior italià, el qual hem esmentat abans. Com que l'autor demostra un cert interès accentuat tant per França com per Itàlia, les dues opcions serien vàlides.

Ens queda veure fins a quin punt la novetat polifònica flamenca del segle XV formà part dels amplis i diversificats coneixement musicals de l'autor anònim. Al Curial e Güelfa trobem precisament dos fragments que ens donen la clau per determinar el caràcter estilístic de la música de què Joanot Martorell ens havia proporcionat ja una insinuació prou contundent. En el primer fragment llegim:

\begin{abstract}
Aprés d'aquesta, ja pus prop de Baco, havia una altra reyna e sonava uns òrguens e cantava ab tanta dolçor de melodia, que yo no crech que millor so ne millor cant fos jamés, ne sia ara, ne pusca ésser d'ací avant. Stàvan-li davant tres donzelles, les quals ab diverses veus cantant se concordàvan ab ella, e certes, si los àngels cantaven davant lo Salvador, major dolçor no porien mostrar (Curial 1933, III: 176).
\end{abstract}

Al capítol 98 del mateix llibre, hi trobem, encara, una nova referència: «E mentre callant en aquest parays estiguessen, oynts celestials ocells (a lur parer), qui cants angelicals, en diverses maneres de melodia, armònicament feyen, veren una deia venir ab una cara molt resplandent...». Al primer fragment se'ns parla de «diverses veus» que «es concordàvan», és a dir, que ens trobem davant una interpretació de música polifònica. Però, el fragment comença amb «una altra reyna» que cantava «ab tanta dolçor de melodia». Això indica una manera de cantar típica de la polifonia del segle XV: hi ha la veu principal, o portador del cantus firmus -que en deien tenor (aquí, doncs, «la reyna») - a la que s'hi afegeixen «les tres donzelles» que $\mathrm{amb}$ «diverses veus cantant se concordàvan ab ella». Es descriu amb precisió una composició de quatre veus, amb una veu directiva acompanyada de tres altres veus que es mouen individualment - «en diverses maneres de melodía»- entorn de la veu principal. I el fet que tant «la reyna» com «les tres donzelles» canten amb «tanta» $\mathrm{O}$ «major dolçon» és una referència a la sonoritat eufònica, que els compositors anglesos havien començat a practicar i que fou desenvolupada fins a cims inaudits pels polifonistes flamencs sota la influència cultural que emanava de la cort de Borgonya. I com que tot indica que les

13 A aquest fragment fan també menció Ferrando \& Martín (2010: 796), quan tracten de «referències al concepte musical acord». 
Bob de Nijs. La música polifònica flamenca del segle XV a les novel les clàssiques catalanes Tirant lo Blanc \& Curial e Güelfa

quatre veus cantaven alhora -o havien començat a cantar al mateix moment-, podem excloure la forma de l'imitatio com a base compositiva. El que canten els quatre personatges al Curial és un cant polifònic madur, que durant molt de temps va ser practicat d'una manera ininterrompuda.

Per altra banda, els fragments que al Curial ens expliquen amb tota precisió l'estil de la música polifónica que es practicava al temps de la redacció de la novel la, estan situats en un context molt curiós que val la pena analitzar amb més detall.

El primer forma part de la descripció d'una visió que tingué el mateix Curial. Encara que ens és presentada com un somni, la descripció il'evolució de les imatges visionàries són massa estructurades per a correspondre a un producte del subconscient (Curial 1933, III: 174-179). El segon fragment també es troba com a part d'una visió. Aquesta vegada, però, li toca a Güelfa -i a la seva companya, «la abadessa»- el fet de veure's davant unes imatges estranyes: totes dues «foren preses de tan estranya son, que ls fonch vijares que may dormit no haguessen» (Curial 1933, III: 221). La visió se situa en «una molt delectable praderia» on li és revelat el retorn de Curial (Curial 1933, III: 221-231). Les dues escenes están poblades de déus i deesses pagans o d'herois de les mitologies gregues i germàniques. Però hi apareixen també al legories personificades a la manera de les que apareixen al Roman de la Rose (com per exemple Papelardie, Dame Oiseuse, Courtoisie, Déduit,...). A la visió de Curial, les donzelles que formen part del seguici de déus i deesses tenien brodats els seus noms als pits: «Ortografia, Ethimologia, Diassintàstica e Prosidia»; o «Probäbilis, Demostrativa e Sophistica»; i les donzelles que canten es diuen «segons llurs cartells: Organico Flatu, Armonica voce, Ritmica Pulsu». Encara que aquestes últimes puguin correspondre als tres tipus de música segons la classificació de sant Isidor de Sevilla (Etomologies, llibre 3, cap. XIX), queda ben clar que l'autor del Curial hi vol representar en forma al legòrica tota una referència a la música en les expressions màximes de la seva época, és a dir: la música polifònica que en aquell moment novel lístic s’interpreta.

Tot això ens recorda presències semblants al Tirant, quan l'autor introdueix unes escenes fantàstiques on intervé una al legoria personificada, al capítol CLXXXX, quan parla Sperança, seguida per aparicions de Morgana, del «rey Artús» i de tota la faràndula... Tot això, farcit de diàlegs, dura fins al capítol CCII, i, de fet, contradiu, amb les referències de simbolismes d'època medieval tardana -J. Huizinga no és mai lluny...-, la tendència realista de la novel la de Martorell. Es tracta més aviat d'una intercalació de caràcter teatral que ha de realçar la cort bizantina on es troba l'heroi de la novel la. ${ }^{14}$ Si mirem les dues escenes del Curial, amb la introducció de tota mena de personatges d'origen mític o al legòric, constatem que l'autor hi accentua més el caràcter visionari, el que fa més difícil de descobrir-ne el teatre, però no oblidem que tota escenificació, sigui de teatre o de pel lícula, crea una fascinació que no s'aparta molt del somni. A més, hi ha el fet que tant la Güelfa com l'abadessa tenen exactament el mateix somni: es podria dir, doncs, que miren la mateixa representació teatral... Els dos quadres, repartits entre els dos personatges novel lístics, Curial i

14 Martí de Riquer (Martorell \& Galba 1982: 61) no es va pronunciar categòricament sobre «el caràcter fantàstic o real que Martorell volgués donar a aquest episodi».

SCRIPTA, Revista internacional de literatura i cultura medieval i moderna, núm. 2 / desembre 2013 / pp. 34-45

ISSN: 2340-4841 · doi:10.7203/SCRIPTA.2.3100 
Bob de Nijs. La música polifònica flamenca del segle XV a les novel les clàssiques catalanes

Tirant lo Blanc \& Curial e Güelfa

Güelfa -i aquesta amb la seva companya, perquè sembla que l'autor hagi volgut obsequiar tots dos de manera igual, amb una creació escènica-, tenen, però, un afegit particular: la música.

Les presències musicals a tota mena d'espectacles, com les escenificacions religioses i festivitats públiques, no eren excepcionals al segle XV. Una qüestió, però, no queda clara i forma alhora un interrogant intrigant: es va inventar l'autor del Curial ell mateix l'escena esmentada més amunt, amb els personatges cantants? $\mathrm{O}$ va descriure una escenificació vista o experimentada en circumstànies viscudes? Esguardant el caràcter cultural del muntatge i l'estil musical polifònic que podem deduir de les definicions precises, en aquest cas ens podríem imaginar un ambient palatí, de cort. Aquest supòsit ens podria dirigir l'atenció als arxius de comptabilitat de les corts, principalment italianes, on, al segle XV, es conreava efectivament la música polifònica present a la novel la. Si als llibres de comptabilitat -si és que han sobreviscut les vicissituds de la història- es pogués trobar la descripció amb l'ajust de comptes d'alguna escenificació semblant, ens trobaríem tal volta més a prop del nostre autor... Esperem... 
Bob de Nijs. La música polifònica flamenca del segle XV a les novel les clàssiques catalanes

Tirant lo Blanc \& Curial e Güelfa

\section{Bibliografia}

Bossuyt, I. (1994) De Vlaamse Polyfonie, Leuven/Lovaina, Davidsfonds.

Curial e Güelfa, a cura de R. Aramon i Serra, 3 vols., Barcelona, Barcino.

Ferrando Moral, A. L. \& Martín Pascual, L (2010) «E açò són les muses quant al sonar e cantar. Algunes nocions de teoria musical en autors catalans del segle XV», dins Actas del XIII Congreso Internacional de la Asociación Hispánica de Literatura Medieval, Valladolid, Ayuntamiento/ Universidad, p. 787-799.

Festa, R. (2012) Laus Polyphoniae, Anvers.

Huizinga, J. (1919): Herfsttij der Middeleewnen, Harlem, H. D. Tjeenk Willink \& Zoon N.V.

Martorell, J. \& Galba, M. J. de (1982) Tirant lo Blanc i altres escrits de Joanot Martorell, a cura de M. de Riquer, Barcelona, Ariel.

Martorell, J. \& Galba, M. J. de (1990) Tirant lo Blanch, a cura d'A. Hauf i V. J. Escartí, València, Generalitat Valenciana.

Averintsev, S. S. (1988) «La bellesa com a santedat», El Correu de Barcelona (juliol 1988, p. 8-11).

Jesús Villalmanzo \& Jaime J. Chiner (1992), La Pluma y la Espada, València, Ajuntament.

Weber, J. F. (2000): Guillaume Dufay, en Laus Polyphoniae, Anvers. 